\section{Prevalence of youth access to alcohol or a gun in the home}

\author{
M H Swahn, B J Hammig, R M Ikeda
}

Injury Prevention 2002;8:227-230

\begin{abstract}
Objectives: To estimate the national prevalence of youth access to alcohol, a gun, or both alcohol and a gun, in their home and to describe the demographic characteristics associated with access to either alcohol or a gun.

Methods: Cross sectional data from the 1995 in-home survey of the National Longitudinal Study of Adolescent Health, which used a nationally representative randomly selected school based sample ( $n=18924$ ) of adolescents in grades 7-12, were analyzed. The current analyses were restricted to those adolescents $12-18$ years of age $(n=18454)$. Crude logistic regression analyses was used to determine the demographic characteristics associated with access to alcohol or a gun in the home. Results: Overall, $28.7 \%$ of US adolescents reported having easy access to alcohol in the home. Availability of alcohol was associated with race/ethnicity, mother's education, family structure, and welfare status. Similarly, $24.3 \%$ of US adolescents reported easy access to a gun in the home. Availability of a gun in the home was associated with gender, race/ethnicity, mother's education, family structure, and welfare status. Among those that reported that a gun was available in their home, most reported availability of a shotgun $(63.0 \%)$ followed by a rifle $(61.3 \%)$, handgun $(57.3 \%)$, and other gun $(16.4 \%)$. Ten per cent of adolescents reported availability of both alcohol and a gun in their home. Conclusions: One quarter of US adolescents reported easy access to either alcohol or a gun in their home. Given the risks associated with the misuse of alcohol and guns among adolescents, efforts to increase public awareness of the availability of alcohol and guns in the home are needed.

Methods: Cross sectional data from the 1995 in-home survey of the National Longitudinal Study of
\end{abstract}

See end of article for authors' affiliations
Correspondence to: Mailstop K-60, National Center for Injury Prevention and Control, CDC, 4770 Buford Highway, Atlanta, GA 30341-3724, USA; mswahn@cdc.gov
$\mathrm{T}$ he three leading causes of death in 1998 for youth between ages 12 and 18 were unintentional injuries, homicides, and suicides. ${ }^{1}$ Many of these deaths involved alcohol or firearms. For example, in 1999, more than one third (35.1\%) of motor vehicle crashes involving youth ages 15-20 were attributed to alcohol use. ${ }^{2}$ Alcohol consumption has also been linked to violence, ${ }^{3-5}$ violence related injury, ${ }^{6}$ and suicide $^{7}$ among youth. It is well documented that most homicides and suicides among youth involve firearms $(80.9 \%$ and $59.8 \%$, respectively). ${ }^{1}$

Findings from national surveys show that the majority of adolescents $(88 \%)$ perceive alcohol to be available to them ${ }^{8}$ and about one third of adolescents perceive guns to be available. ' Currently, little is known about the availability of alcohol or guns to adolescents in their homes, although some reports suggest that the home may be a source of either alcohol ${ }^{10}$ or guns. ${ }^{11}$ One study found that $66 \%$ of guns used in suicide attempts and unintentional injuries among children and adolescents were stored in the home of the victim. ${ }^{12}$

In this paper we report the availability of alcohol and/or a gun in the home for a nationally representative sample of US adolescents in grades 7 through 12. The associations between demographic characteristics and access to alcohol or a gun are also presented.

\section{METHODS}

Data used for the analyses were collected as part of the National Longitudinal Study of Adolescent Health (Add Health) conducted by the Carolina Population Center at the University of North Carolina at Chapel Hill. Details regarding the survey methodology are described elsewhere. ${ }^{13}$ In brief, this survey used a multistage stratified cluster design resulting in a nationally representative sample of US adolescents selected from 80 high schools and 52 middle schools, both public and private. Incorporating systematic sampling methods and implicit stratification into the Add Health study design ensured that this sample was representative of US schools with respect to region of country, urbanicity, school type, ethnicity, and school size. Following local Institutional Review Board approval of the study and receipt of parental consent, each eligible student was asked to complete an in-school survey. The participation rate was $75.6 \%$. All students at each school were then stratified by grade and gender. Within each stratum investigators randomly selected students to be included in a second and much more detailed interview. The selected students were asked to complete a 90 minute in-home interview. In addition, one of the student's parents or care givers also completed a separate in-home questionnaire. Eighty per cent of students selected in this second stage completed an interview sometime between April and December 1995 ( $n=18$ 924). About 85\% of the parents or care givers (most often the biological mother) completed a parent questionnaire during the same time period. The current analysis presents findings based on the in-home interviews and is limited to those adolescents between 12 and 18 years of age $(n=18454)$.

\section{Measures}

The interviews asked all student participants, "Is alcohol easily available to you in your home?" They also asked "Is a gun easily available to you in your home?" Respondents answered "yes" or "no". Students with access to a gun were asked, "What kind of gun is available?" Respondents could indicate all categories that applied: handgun, shotgun, rifle, or other. We created four mutually exclusive categories of students: those with access to alcohol only, those with access to a gun only, those with access to both alcohol and a gun, and those with access to neither alcohol nor a gun.

Demographic information collected included: gender, age, race/ethnicity, family structure, mother's education, and the family's economic situation. Race and ethnicity were combined and coded as follows: (1) Hispanic, (2) non-Hispanic 
Table 1 Demographic characteristics of adolescents reporting easy availability of alcohol or a gun in the home

\begin{tabular}{|c|c|c|c|c|c|c|}
\hline \multirow[b]{2}{*}{ Measures } & \multirow[b]{2}{*}{ No } & \multirow{2}{*}{$\begin{array}{l}\text { Weighted } \\
\text { population (\%) }\end{array}$} & \multicolumn{2}{|c|}{ Reporting availability of alcohol } & \multicolumn{2}{|c|}{ Reporting availability of a gun } \\
\hline & & & $\%$ & OR $(95 \% \mathrm{Cl})$ & $\%$ & OR $(95 \% \mathrm{Cl})$ \\
\hline Total & 18454 & 100.00 & 28.7 & & 24.3 & \\
\hline \multicolumn{7}{|l|}{ Gender } \\
\hline Female & 9448 & 49.5 & 28.7 & 1.00 & 18.0 & 1.00 \\
\hline Male & 9006 & 50.5 & 28.7 & $1.00(0.91$ to 1.11$)$ & 30.6 & 2.01 (1.79 to 2.25$)$ \\
\hline \multicolumn{7}{|l|}{ Age (years) } \\
\hline $12-14$ & 5023 & 34.6 & 26.4 & 1.00 & 22.0 & 1.00 \\
\hline $15-16$ & 7022 & 34.4 & 30.1 & 1.20 (1.03 to 1.40$)$ & 24.2 & 1.13 (0.93 to 1.32$)$ \\
\hline $17-18$ & 6409 & 31.1 & 29.7 & 1.17 (1.00 to 1.38$)$ & 27.1 & 1.32 (1.04 to 1.69$)$ \\
\hline \multicolumn{7}{|l|}{ Race/ethnicity } \\
\hline Non-Hispanic African American & 3907 & 15.6 & 20.6 & 1.00 & 14.0 & 1.00 \\
\hline Non-Hispanic white & 9757 & 67.3 & 31.0 & 1.73 (1.46 to 2.05$)$ & 29.9 & 2.62 (2.03 to 3.38 ) \\
\hline Non-Hispanic other & 1606 & 5.3 & 33.3 & 1.92 (1.45 to 2.56$)$ & 13.1 & $0.92(0.65$ to 1.31$)$ \\
\hline Hispanic & 3084 & 11.8 & 24.6 & 1.25 (1.03 to 1.53 ) & 10.8 & $0.75(0.56$ to 0.99$)$ \\
\hline Missing & 100 & & & & & \\
\hline \multicolumn{7}{|l|}{ Mother's education } \\
\hline$<$ High school & 3222 & 17.2 & 21.3 & 1.00 & 17.5 & 1.00 \\
\hline High school/GED Diploma* & 5352 & 32.8 & 26.3 & $1.32(1.15$ to 1.51$)$ & 26.6 & 1.71 (1.40 to 2.08 ) \\
\hline Post high school & 5030 & 28.3 & 29.3 & 1.53 (1.31 to 1.79 ) & 26.9 & $1.73(1.42$ to 2.11$)$ \\
\hline College degree & 4337 & 21.7 & 36.9 & $2.17(1.81$ to 2.58$)$ & 22.6 & 1.37 (1.09 to 1.73 ) \\
\hline Missing & 513 & & & & & \\
\hline \multicolumn{7}{|l|}{ Family structure } \\
\hline Single parent & 5484 & 28.8 & 24.2 & 1.00 & 17.0 & 1.00 \\
\hline Two biological parents & 9523 & 53.8 & 30.8 & 1.40 (1.26 to 1.56$)$ & 28.6 & 1.95 (1.70 to 2.24 ) \\
\hline Two parents & 2380 & 11.7 & 30.9 & 1.41 (1.19 to 1.67$)$ & 24.0 & 1.54 (1.31 to 1.82 ) \\
\hline Other & 1067 & 5.7 & 26.7 & 1.14 (0.95 to 1.38$)$ & 21.8 & 1.36 (1.08 to 1.71$)$ \\
\hline \multicolumn{7}{|l|}{ Receive welfare } \\
\hline Yes & 1964 & 11.0 & 21.7 & 1.00 & 14.1 & 1.00 \\
\hline No & 15942 & 89.0 & 29.5 & 1.51 (1.28 to 1.78$)$ & 25.6 & 2.10 (1.70 to 2.59$)$ \\
\hline Missing & 548 & & & & & \\
\hline
\end{tabular}

white, (3) non-Hispanic African-American, and (4) nonHispanic other (Native American, Asian, or Pacific Islander).

\section{Analytic methods}

Prevalence estimates were obtained for the availability of alcohol and/or a gun in the home. Crude logistic regression analyses determined the association between each of the demographic characteristics and the availability of either alcohol or a gun. We used the SUDAAN statistical software package for all statistical analyses in order to accommodate the complex sampling design and to provide accurate standard errors for the weighted analyses. ${ }^{14}$

Table 2 Percent reporting easy availability in the home of alcohol only, a gun only, both alcohol and a gun, or neither alcohol nor a gun, by demographic characteristics; values are per cent $(95 \% \mathrm{Cl})$

\begin{tabular}{|c|c|c|c|c|}
\hline Measures & $\begin{array}{l}\text { Availability of alcohol } \\
\text { only }\end{array}$ & $\begin{array}{l}\text { Availability of a gun } \\
\text { only }\end{array}$ & $\begin{array}{l}\text { Availability of alcohol } \\
\text { and a gun }\end{array}$ & $\begin{array}{l}\text { Availability of neither } \\
\text { alcohol nor a gun }\end{array}$ \\
\hline Total & 18.5 (16.8 to 20.2 ) & $14.1(12.5$ to 15.8$)$ & $10.2(9.0$ to 11.3$)$ & 57.2 (54.9 to 59.5 ) \\
\hline \multicolumn{5}{|l|}{ Gender } \\
\hline Females & 20.8 (18.8 to 22.7$)$ & $10.1(8.8$ to 11.5$)$ & $7.9(6.8$ to 8.9$)$ & $61.2(58.9$ to 63.5$)$ \\
\hline Males & $16.3(14.4$ to 18.2$)$ & 18.1 (15.9 to 20.3 ) & 12.4 (10.8 to 14.0$)$ & $53.2(50.3$ to 56.2$)$ \\
\hline \multicolumn{5}{|l|}{ Age (years) } \\
\hline $12-14$ & $17.7(15.2$ to 20.2$)$ & $13.3(10.8$ to 15.8$)$ & $8.6(7.1$ to 10.1$)$ & $60.4(57.1$ to 63.7$)$ \\
\hline $15-16$ & 19.5 (17.2 to 21.7$)$ & 13.6 (11.6 to 15.5$)$ & $10.6(9.3$ to 11.9$)$ & $56.3(53.7$ to 59.0$)$ \\
\hline $17-18$ & 18.3 (16.2 to 20.3$)$ & 15.8 (13.2 to 18.3 ) & $11.4(9.7$ to 13.0$)$ & $54.6(51.6$ to 57.6$)$ \\
\hline \multicolumn{5}{|l|}{ Race/ethnicity } \\
\hline Non-Hispanic African American & 14.1 (12.1 to 16.2$)$ & $7.5(5.8$ to 9.2$)$ & $6.5(5.2$ to 7.8$)$ & 71.9 (68.6 to 75.2$)$ \\
\hline Non-Hispanic white & $18.9(16.7$ to 21.0$)$ & $17.9(15.8$ to 19.9$)$ & $12.1(10.6$ to 13.5$)$ & $51.2(48.8$ to 53.6$)$ \\
\hline Non-Hispanic other & 26.6 (22.2 to 31.1$)$ & $6.0(4.0 \text { to } 8.1)^{\prime}$ & $6.8(4.7$ to 8.8$)$ & 60.6 (55.4 to 65.7$)$ \\
\hline Hispanic & 18.8 (16.2 to 21.3$)$ & $5.1(3.7$ to 6.5$)$ & $5.8(4.4$ to 7.1$)$ & 70.4 (67.4 to 73.4$)$ \\
\hline \multicolumn{5}{|l|}{ Mother's education } \\
\hline$<$ High school & $14.4(12.5$ to 16.2$)$ & $10.6(8.5$ to 12.8$)$ & $6.9(5.4$ to 8.5$)$ & 68.1 (64.9 to 71.3$)$ \\
\hline High school/GED Diploma* & 15.8 (13.9 to 17.7$)$ & $16.2(14.1$ to 18.3$)$ & $10.5(9.0$ to 11.9$)$ & 57.5 (54.7 to 60.4 ) \\
\hline Post high school & 18.1 (16.4 to 19.8$)$ & 15.7 (13.8 to 17.6$)$ & $11.1(9.5$ to 12.8$)$ & 55.1 (52.4 to 57.7$)$ \\
\hline College degree & 26.4 (22.9 to 30.0$)$ & 12.1 (9.6 to 14.5$)$ & 10.5 (8.8 to 12.2$)$ & 51.0 (48.1 to 54.0 ) \\
\hline \multicolumn{5}{|l|}{ Family structure } \\
\hline Single parent & 17.3 (15.5 to 19.0$)$ & $10.0(8.6$ to 11.4$)$ & $6.9(5.8$ to 7.9$)$ & $65.9(63.3$ to 68.5$)$ \\
\hline Two biological parents & 19.3 (17.0 to 21.6$)$ & 17.1 (15.0 to 19.2$)$ & 11.5 (10.0 to 13.0$)$ & 52.1 (49.7 to 54.5$)$ \\
\hline Two parents & $19.4(17.3$ to 21.5$)$ & 12.5 (10.2 to 14.8$)$ & $11.5(9.4$ to 13.6$)$ & 56.6 (52.9 to 60.2$)$ \\
\hline Other & 15.2 (12.7 to 17.8$)$ & $10.3(7.8$ to 12.8$)$ & 11.5 (8.7 to 14.3$)$ & 63.0 (58.4 to 67.5$)$ \\
\hline \multicolumn{5}{|l|}{ Receive welfare } \\
\hline Yes & 17.1 (14.6 to 19.7) & $9.6(7.3$ to 11.8$)$ & $4.5(3.3$ to 5.8$)$ & 68.8 (65.6 to 72.0 ) \\
\hline No & 18.7 (16.9 to 20.6$)$ & $14.9(13.1$ to 16.6$)$ & $10.7(9.5$ to 11.9$)$ & $55.7(53.5$ to 58.0$)$ \\
\hline
\end{tabular}




\section{RESULTS}

Overall, $28.7 \%$ of US adolescents reported easy availability of alcohol in the home. Availability of alcohol in the home was associated with age, race/ethnicity, mother's education, family structure, and welfare status (see table 1).

Nearly one quarter $(24.3 \%)$ of adolescents reported easy access to a gun in the home. Availability of a gun in the home was associated with gender, race/ethnicity, mother's education, family structure, and welfare status (see table 1). Among those who reported that a gun was available in their home, most reported availability of a shotgun $(63.0 \%)$ followed by a rifle $(61.3 \%)$, handgun $(57.3 \%)$, and other gun $(16.4 \%)$.

More than half $(57.2 \%)$ of the adolescents reported that neither alcohol nor a gun was easily available to them, $18.5 \%$ reported availability of alcohol only, $14.1 \%$ reported availability of a gun only and $10.2 \%$ reported availability of both alcohol and a gun in the home (see table 2 ).

\section{DISCUSSION}

Overall, $28.7 \%$ of US adolescents reported easy availability of alcohol in the home, $24.3 \%$ reported availability of a gun in the home, and $10.2 \%$ reported availability of both alcohol and a gun in the home. Our findings regarding the availability of alcohol or a gun are much lower than estimates from previous studies. ${ }^{89}$ These differences likely reflect the fact that our findings are limited to availability in the home.

Our study is the first to examine adolescents perceptions of in-home availability to alcohol or guns in a nationally representative sample. Of particular interest are the findings indicating that adolescents who are white, who live with two parents, who are not receiving welfare, and who have mothers that had attained a high school degree or higher, were more likely to report access to alcohol and guns. These findings are not surprising given the demographic characteristics of adults who drink alcohol ${ }^{15}$ or have a gun in their home. ${ }^{16}$ Accordingly, the demographic characteristics of adolescents who reported access to alcohol or a gun simply reflect those demographic characteristics of adults who are alcohol users or gun owners.

It is also intriguing to note that the prevalence of in-home availability of a gun or alcohol is comparable $(24.3 \%$ and $28.7 \%$, respectively). This finding is contrary to the perception that it is more common for adolescents to find alcohol, rather than guns, easily available to them in their homes. Moreover, our findings show that one in 10 adolescents (10.2\%) report in-home availability of both alcohol and guns. This finding is troubling given the link between alcohol use, guns, and suicides. For example, suicide victims who used a firearm were found to be five times more likely to have been drinking alcohol before their death than were suicide victims who used different methods.'

The study involves three limitations. First, the study does not corroborate data from participants' self reports with any other sources of information. Second, it is unknown how adolescents interpreted the question "Is alcohol (a gun) easily available to you in your home?" The study did not obtain any information about how the alcohol (or gun) was stored or who owned it. Third, we were not able to determine whether the availability of alcohol or a gun in the home is related to their use. However, it is likely that easy access to these items in the home facilitates their misuse.

Results from other studies have linked availability of alcohol or a gun in the home and its use. One study found that $27 \%$ of alcohol users in ninth grade reported their homes as the source of the alcohol consumed during their last drinking occasion. ${ }^{10}$ Likewise, findings from a retrospective case series of injuries among children and adolescents in King County, Washington, determined that $84 \%$ of the guns used in suicides and suicide attempts and $42 \%$ of the guns involved in unintentional injuries were stored in the victim's home. ${ }^{12}$

\section{Key points}

- About one in four US adolescents report having easy access to alcohol or a gun in the home.

- About one in 10 US adolescents report having easy access to alcohol and a gun in the home.

- Easy access to alcohol and guns are more common among adolescents who are white, who live with two parents, who do not receive welfare, and who have a mother that had attained at least a high school degree.

- Given the risks associated with the misuse of alcohol and guns among adolescents, efforts to increase public awareness of the availability of alcohol and guns in the home are needed.

Our findings highlight three important issues. First, the home is an important and underestimated source of both alcohol and guns among adolescents. Second, prevention efforts that seek to decrease access and misuse of alcohol and guns need to target white middle class families who are traditionally not considered high risk. Third, the relatively large number of adolescents (2.1 million) living in households with access to both alcohol and guns, as well as the combined injury risk when both alcohol and guns are present, justify prevention programs focusing on increasing safe storage practices of alcohol and guns simultaneously rather than either alone.

\section{IMPLICATIONS FOR PREVENTION}

Research shows that current prevention and intervention strategies focusing on traditional parent education, even those delivered by physicians, are relatively ineffective at removing guns from homes with children, or at changing the firearm storage practices by parents. ${ }^{17-19}$ Similarly, despite laws prohibiting youth under age 21 to purchase alcohol, or for adults over 21 to provide alcohol to minors, adolescents continuously report that alcohol is very easy to obtain. ${ }^{8}$ Therefore, media campaigns may be a productive and innovative way to inform the public of the risks associated with the misuse of alcohol and guns among adolescents while also pointing out that a substantial number of adolescents, one in four, find alcohol or a gun easily available to them in their home.

Prevention programs are already using the media to inform the community, parents, and older siblings regarding the laws prohibiting sales of alcohol to minors, legal enforcement efforts, the potential penalties associated with providing alcohol to minors, and also the negative consequences of alcohol use..$^{20}$ It is unclear if similar strategies have been used with respect to increasing safe gun storage practices. However, a media campaign may be a particularly productive strategy to improve safe gun storage practices since it could target married women with children who tend to be unaware that guns in their homes may be stored in an unsafe manner. ${ }^{21}$ In addition, a media campaign can highlight that access to alcohol and guns are more common in intact middle class families while emphasizing that the risks associated with the misuse of alcohol and guns not only pertain to an adolescent living in a particular household but also to that of friends, siblings, parents, and others who may visit the home. Raising public awareness of these issues, and making parents discuss them, will be necessary in order to increase safe storage practices of alcohol and guns.

\section{ACKNOWLEDGEMENTS}

This research is based on data from the Add Health project, a program project designed by J Richard Udry (PI) and Peter Bearman, and funded by grant P01-HD31921 from the National Institute of Child Health and Human Development to the Carolina Population Center, University of North Carolina at Chapel Hill, with cooperative funding participation by the National Cancer Institute; the National Institute 
of Alcohol Abuse and Alcoholism; the National Institute on Deafness and Other Communication Disorders; the National Institute on Drug Abuse; the National Institute of General Medical Sciences; the National Institute of Mental Health; the National Institute of Nursing Research; the Office of AIDS Research, NIH; the Office of Behavior and Social Science Research, NIH; the Office of the Director, NIH; the Office of Research on Women's Health, NIH; the Office of Population Affairs, DHHS; the National Center for Health Statistics, Centers for Disease Control and Prevention, DHHS; the Office of Minority Health, Office of Public Health and Science, DHHS; the Office of the Assistant Secretary for Planning and Evaluation, DHHS; and the National Science Foundation. Persons interested in obtaining data files from the National Longitudinal Study of Adolescent Health should contact Jo Jones, Carolina Population Center, 123 West Franklin Street, Chapel Hill, NC 27516-3997 (email jo_jones@unc.edu).

\section{Authors' affiliations}

M H Swahn, R M Ikeda, Division of Violence Prevention, National Center for Injury Prevention and Control, Centers for Disease Control and Prevention, Atlanta

B J Hammig, Department of Health Education and Recreation, Southern Illinois University, Carbondale

\section{REFERENCES}

1 Centers for Disease Control and Prevention (CDC). 1998 Leading causes of deaths report. Data from National Vital Statistics System and US Bureau of Census: statistics compiled by Office of Statistics and Programming, NCIPC, 2001

2 National Highway Traffic Safety Administration (NHTSA). 1999 Youth fatal crash and alcohol facts (cited 20 September 2001; http://www.nhtsa.dot.gov/people/injury/alcohol/ $1999 \% 20$ YFCAF\%20final\%20web/page6.htmll.

3 Ellickson P, Saner H, McGuigan KA. Profiles of violent youth: substance use and other concurrent problems. Am J Public Health 1997;87:985-91.

4 Orpinas PK, Basen-Engquist K, Grunbaum JA, et al. The co-morbidity of violence-related behaviors with health-risk behaviors in a population of high school students. J Adolesc Health 1995;16:216-25.

5 White HR, Loeber R, Stouthamer-Loeber M, et al. Developmental associations between substance use and violence. Development and Psychopathology 1999;11:75-803.
6 Malek MK, Bei-Hung C, Davis TC. Self-reported characterization of seventh-grade students' fights. J Adolesc Health 1998;23:103-9.

7 Brent DA, Perper JA, Allman C. Alcohol, firearms, and suicide among youth: temporal trends in Allegheny County, Pennsylvania, 1960-1983. JAMA 1987;257:3369-72

8 Johnston LD O'Malley PM, Bachman JG. National survey results on drug use from the Monitoring the Future Study, 1975-1998. Volume I, secondary school students. Rockville, MD: National Institute on Drug Abuse, 1999

9 American School Health Association (ASHA). The National Adolescent Student Health Survey: a report on the health of America's youth. Oakland, CA: Third Party Publishing Company, 1989

10 Wagenaar AC, Tomey TL, Murray DM, et al. Sources of alcohol for underage drinkers. J Stud Alcohol 1996;57:325-33.

11 Callahan CM, Rivara FP. Urban high school youth and handguns: a school based survey. JAMA 1992;267:3038-42.

12 Grossman DC, Reay DT, Baker SA. Self-inflicted and unintentional firearm injuries among children and adolescents: the source of the firearm. Arch Pediatr Adolesc Med 1999;153:875-8.

13 Bearman PS, Jones J, Udry JR. The National Longitudinal Study of Adolescent Health: research design 1997 (cited 20 September 2001; http://www.cpc.unc.edu/projects/addhealth/design.html).

14 Shah BV, Barnwell BG, Bieler GS. SUDAAN user's manual: software for analysis of correlated data. Research Triangle Park, NC: Research Triangle Institute, 1995.

15 Substance Abuse and Mental Health Services Administration Summary of findings from the 2000 National Household Survey on Drug Abuse. Rockville, MD: Office of Applied Studies, NHSDA Series H-13, AHHS Publication No (SMA) 01-3549, 2001

16 Maguire K, Pastore AL, eds. Sourcebook of criminal justice statistics, 2001 (cited 5 February 2002; http://www.albany.edu/sourcebook/)

17 Brent DA, Baugher M, Birmaher B, et al. Compliance with recommendations to remove firearms in families participating in a clinical trial for adolescent depression. J Am Acad Child Adolesc Psychiatry 2000;39:1220-6

18 Grossman DC, Cummings P, Koepsell TD, et al. Firearm safety counseling in primary care pediatrics: a randomized controlled trial. Pediatrics 2000:106:22-6.

19 Oatis PJ, Fenn Buderer NM, Cummings O, et al. Pediatric practice based evaluation of the steps to prevent firearm injury program. Inj Prev 1999;5:48-52.

20 Pacific Institute for Research and Evaluation. Strategies for reducing third party transactions of alcohol to underage youth. Prepared for the OJJDP Enforcing the Underage Drinking Laws Program (cited 28 January 2002; http://www.udetc.org/Publications.html)

21 Azrael D, Miller M, Hemenway D. Are household firearms stored safely? It depends on whom you ask. Pediatrics 2000;106:e30.

\section{LACUNAE}

\section{Iranian road deaths}

In the deadliest day of road accidents in Iran, 122 people died, and 1855 were injured yesterday in more than 900 different accidents, state run Tehran television reported. The broadcast said that such a high number of traffic casualties was unprecedented in this country. About 350 ambulances recovered casualties from the 933 accidents across the country, it said. Iran has one of the highest rates of road accidents in the world, with more than 200000 accidents and about 15000 deaths each year. Specialists blame old and unsafe vehicles, disregard for regulations, and inadequate emergency services. Few details were made available on specific accidents (this is the exact text published in the Boston Globe on 26 March 2002, contributed by Anara Guard).

\section{Dog mauling convictions}

A San Francisco couple were found guilty in March of the death of a neighbour, who was fatally mauled by the couple's dog in their apartment building in 2001. One person was found guilty of second degree murder, involuntary manslaughter, and owning a mischievous animal that killed a 33 year old (fit) woman who lived down the hall from her in the San Francisco apartment building. She faces a 15 year prison sentence. Another person, who was not present at the time of the attacks, was convicted of involuntary manslaughter and owning a mischievous animal. He could go to prison for up to four years. The guilty verdict, which came after five weeks of trial in Los Angeles Superior Court, represented the first time in California history that someone was convicted of second degree murder for the actions of a pet (contributed by Ian Scott). 